\title{
Increased levels of antibodies against heat shock proteins in stroke patients
}

\author{
Zyta Banecka-Majkutewicz1, Michał Grabowski², Leszek Kadziński², Aliaksei Papkov², Alicja \\ Węgrzyn ${ }^{3}$ and Bogdan Banecki ${ }^{\bowtie}$
}

\begin{abstract}
1Department of Neurology, Medical University of Gdansk, Gdańsk, Poland; 2Department of Molecular and Cellular Biology, Intercollegiate Faculty of Biotechnology of the University of Gdansk and Medical University of Gdansk, Gdańsk, Poland; '3Department of Microbiology, University of Szczecin, Szczecin, Poland
\end{abstract}

\begin{abstract}
Ischemic stroke is the second leading cause of death worldwide. One of the main risk factors of the ischemic stroke is atherosclerosis which is a chronic inflammatory and immune-mediated disease. Bacterial infections generate specific human antibodies against various antigens, including Hsps. It has been demonstrated that Hsps are selectively overexpressed in the atherosclerotic lesions. The amino acid sequence homology between human and bacterial Hsps may lead to an autoimmune response by immunological cross-reaction. Such immune response against Hsps overexpressed in the blood vessels under stressful conditions may contribute to inflammatory processes and subsequent development of atherosclerosis. In this study we determined the antibody levels against bacterial and human Hsp by ELISA in blood plasma obtained from stroke patients. Using ANOVA we analyzed levels of Hsp-antibodies in control and patient groups and correlate them with several stroke risk factors. The group of stroke patients had elevated levels of anti-Hsp antibodies compared to the control group. We also discovered an antibody level increase in patients that previously underwent another stroke. Our data provide evidence that autoimmunity could underlie formation of atherosclerosis plaque leading to stroke.
\end{abstract}

Key words: HSP, Heat Shock Proteins, Stroke, DnaK, DnaJ, GroEL, Hsp70, ELISA

Received: 07 May, 2014; revised: 16 May, 2014; accepted: 27 May, 2014; available on-line: 06 June, 2014

\section{INTRODUCTION}

Heat shock proteins are a family of highly conserved proteins with well-studied structures and functions. Under physiological conditions, they constitute 5-10\% of the total protein level in the cell. Their synthesis is constitutive or induced under stress conditions, i.e. heat shock, oxidative shock, viral infection, NO, UV, ethanol, certain chemicals or exposure to cytokines (Georgopoulos \& Welch, 1993; Pockley, 2001; Xu, 2002, Mehta et al., 2005). The basic functions of Hsp may include protective activity and weakening of the intracellular and extracellular stressors. They are also involved in the synthesis and folding of newly formed proteins and they are involved in many metabolic pathways (Hartl, 1996). A multitude of heat shock protein functions is related to their ability to form complexes with many proteins, abil- ity to induce conformational changes and aid in crossing cellular membranes. Hsp also take part in regulation of apoptosis in the cell (Beere, 2005; Kaźmierczuk et al., 2009). Based on molecular weight, heat shock proteins can be divided into several groups based on molecular weight: small Hsp, Hsp40, Hsp60, Hsp70 and Hsp90 (Kaźmierczuk et al., 2009).

Representatives of small Hsp family are IbpA and IbpB. A characteristic feature of these enzymes is relatively low molecular weight $(12-43 \mathrm{kDa})$ and the presence of a conserved $\alpha$ - crystalline domain. In addition, proteins belonging to this family have oligomeric structure. Small Hsp expression is induced under the influence of stress, such as elevated temperatures. Their function is to prevent irreversible aggregation of denatured proteins (Kuczyńska-Wiśnik et al., 2010).

An example of Hsp40 family member is DnaJ, with a mass $41 \mathrm{kDa}$. DnaJ also belongs to a family of -JDP, i.e. proteins that have a 70 amino acid motif J. DnaJ domain is primarily responsible for the stimulation of ATP hydrolysis of DnaK (Banecki et al., 1996; Nakamoto et al., 2014).

On the other hand, GroEL is a representative of Hsp60 family. Its main function is chaperone activity in the protein synthesis process. Only 84 proteins are predicted to absolutely depend upon GroEL to fold correctly, but these include at least 13 essential proteins.

DnaK is the main protein in the Hsp70 system, displaying ATPase activity. This protein is expressed under physiological growth conditions, but it is largely induced in response to heat shock, oxidative or osmotic stress, and limiting nutrient levels (Dahiya et al., 2014). Proteins belonging to the Hsp70 family are characterized by their N-terminal ATPase domain, a substrate binding domain, and a short C-terminal domain, which could interact with various protein partners, thereby regulating the function of a given chaperone (Rosenzweig et al., 2013; Nakamoto et al., 2014).

Hsp90 family members have over a hundred identified substrates, but they also facilitate steroid hormones' receptor signaling. Activity of Hsp90 affects expression of a number of genes through the activation of protein kinases. Hsp90 level is kept constant under physiological conditions, however, it increases significantly under stress conditions The main inducer of overproduction

e-mail: banecki@biotech.ug.edu.pl

Abbreviations: ANOVA, analysis of variance statistical test; ELISA, enzyme-linked immunosorbent assay; Hsp, heat shock protein; JDP, J-domain protein 
of Hsp90 is oxidative stress that occurs for example in reperfusion (Richter \& Buchner, 2001; Picard, 2005; Caplan et al., 2007; Nakamoto et al., 2014). A bacterial homologue of human Hsp90 is HtpG.

Involvement of heat shock proteins in the pathogenesis and progression of atherosclerosis is undoubtedly complex. Traditional risk factors, such as metabolic disorders or hypertension, increase expression of the Hsp on the surface of endothelial cells in blood vessels. Hsp expression may in turn promote production of cytokines, increased expression of adhesion molecules, and the creation and promotion of the inflammatory response (Berberian et al., 1990; Xu, 2002). The inflammatory response can also be induced due to cross reactivity between human and bacterial Hsp. Hsps also influence activity of the major enzymes of homocysteine metabolism one of the main risk factor of stroke (Grabowski et al., 2012). Induction of immune response against autologous or bacterial heat shock proteins on the surface of the vascular endothelium may lead to endothelial damage, followed by the development of atherosclerotic plaque, which is a cause of serious diseases - heart attack and stroke. They are also involved in development of auto-immunological diseases like rheumatoid arthritis, juvenile idiopathic arthritis and paraneoplastic syndrome (Nishizawa et al., 1996).

\section{MATERIALS AND METHODS}

Specimen collection and preparation. Study population included seventy four stroke patients hospitalized in the Clinic of Adult Neurology of the Medical University of Gdańsk (25 women and 50 men, mean age $69 \pm 15$ years) and twenty one non-stroke members of the control group ( 25 cases, mean age $43 \pm 12$ years). Information about presence of risk factors was collected from records and questionnaire based on interview with a given individual or closest relatives. Blood was collected in the Clinic of the Department of Neurology of the Medical University of Gdańsk (Sawuła et al., 2009). Plasma from each patient was obtained by centrifugation $(2000 \times g$ for $15 \mathrm{~min})$. Samples were frozen and stored at $-70^{\circ} \mathrm{C}$.

Protein purification. Proteins were purified as described (Spence et al., 1989; Woo et al., 1992; Wawrzynów et al., 1995; Banecki et al., 1998).

Enzyme-linked immunosorbent assay. Antibody levels against particular proteins were measured by the ELISA test. Ninety-six-well microtiter plates were coated with GroEL, HtpG, DnaJ, DnaK and Hsp72. After 60 min of incubation at $37^{\circ} \mathrm{C}$, plates were washed with PBS containing $0.05 \%$ Triton $\mathrm{X}-100$. Non-specific binding was blocked with 1\% BSA (Sigma, CAS Number 904846-8) in PBS. After another wash, $50 \mu$ l of serum sample was added and incubated for 1 hour at $37^{\circ} \mathrm{C}$. After washing with PBS containing $0.05 \%$ Triton X-100, the wells were incubated with secondary antibodies conjugated with horseradish peroxidase (Sigma, CAS Number 9003-99-0) for $1 \mathrm{~h}$ at $37^{\circ} \mathrm{C}$. Then the plates were washed and developed with $50 \mu \mathrm{l}$ TMB and incubated for 10 min. The reaction was terminated by adding $50 \mu \mathrm{l} 1 \mathrm{M}$ $\mathrm{H}_{2} \mathrm{SO}_{4}$ and optical density was measured at $450 \mathrm{~nm}$ using an ELISA plate reader (Wallac Victor ${ }^{2} 1420$ ).

Statistical analysis. Data was analyzed using STATISTICA software for Windows v. 10 (StatSoft, USA) using one-way ANOVA statistics. A p-value of $<0.05$ was estimated as statistically significant.

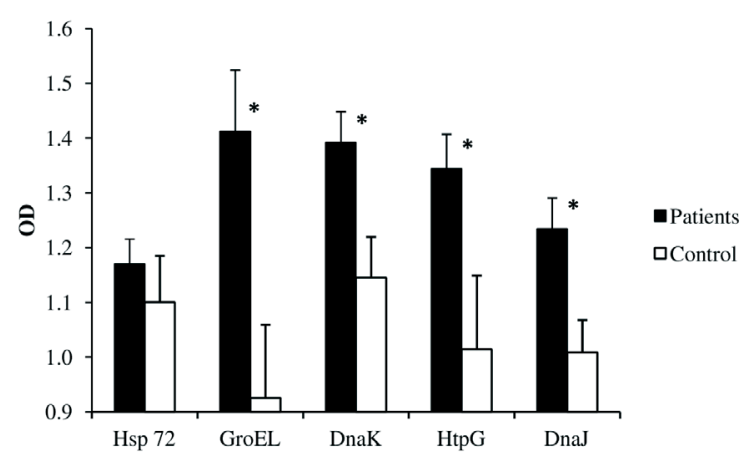

Figure 1. The relative antibody levels against Hsps in patients and control group.

*Indicate $p<0.05$ compared to the control group (ANOVA).

\section{RESULTS}

In our study we have demonstrated an increase in the level of anti-Hsp antibodies against bacterial heat shock proteins, however there was no statistically significant difference in anti-Hsp72 antibodies level between groups $(p>0.05)$ (Fig. 1). Antibody level against Hsp72 was 1.10 in the control and 1.17 in the patient group. Interestingly, only for human recombinant Hsp72 the level of antibodies was not elevated. For all other studied bacterial proteins we have observed higher level of antibodies in stroke patient group. The mean of antibody level against DnaJ reached 1.01 in the control group and 1.23 in the patient group and it is a statistically significant difference $(p=0.047)$. Anti-GroEL antibody level was 0.93 in the control group and 1.41 in the patient group. The group of patients had higher level of antibodies compared to the control group $(p=0.030)$. The mean values of antibody level against DnaK in control and patient groups were 1.15 and 1.39 respectively, and by one-way ANOVA we determined that it is a statistically significant difference $(p=0.041)$. Anti-HtpG antibody level was 1.01 in the control group and 1.34 in the patient group. The difference is statistically significant $(p=0.022)$.

Our results confirm the widely accepted hypothesis that the Hsp-antibodies have an essential role in pathological mechanism of the atherosclerosis and stroke. We assume that previous bacterial infections and subsequent increase in antibody level are a risk factor of stroke. We have analyzed the correlation between risk factors of stroke and antibody levels (Table 1). Interestingly, the level of antibodies against all studied proteins increased in the group of patients that previously underwent an-

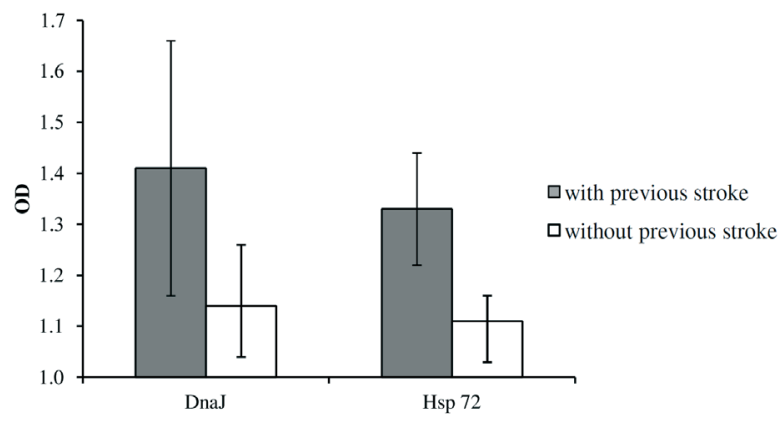

Figure 2. The relative antibody levels against Hsps in group of patients with and without previous stroke. 
Table 1. Relation between antibody level against Hsps and selected risk factors of stroke ( $p$-values for ANOVA).

\begin{tabular}{|c|c|c|c|c|c|}
\hline Risk factors & Hsp72 & DnaJ & HtpG & GroEL & DnaK \\
\hline Previous stroke & 0.046 & $\underline{0.022}$ & 0.326 & 0.145 & 0.145 \\
\hline Carotid artery stenosis & 0.936 & 0.735 & 0.091 & 0.369 & 0.094 \\
\hline Myocardial infarction & 0.904 & 0.828 & 0.062 & 0.562 & 0.395 \\
\hline Smoking & 0.738 & 0.609 & 0.076 & 0.438 & 0.742 \\
\hline Stress & 0.076 & 0.455 & 0.235 & 0.457 & 0.492 \\
\hline Depression & 0.250 & 0.617 & 0.170 & 0.862 & 0.081 \\
\hline Migraine & 0.162 & 0.338 & 0.479 & 0.101 & 0.743 \\
\hline Hypercholesterolemia & 0.232 & 0.958 & 0.705 & 0.685 & 0.947 \\
\hline Coronary artery disease & 0.238 & 0.974 & 0.255 & 0.612 & 0.678 \\
\hline Hypertension & 0.428 & 0.506 & 0.615 & 0.849 & 0.109 \\
\hline Heart defects & 0.489 & 0.253 & 0.902 & 0.434 & 0.356 \\
\hline Vascular diseases & 0.532 & 0.795 & 0.675 & 0.642 & 0.225 \\
\hline Parkinson's disease & 0.618 & 0.977 & 0.303 & 0.791 & 0.171 \\
\hline Atrial fibrillation & 0.713 & 0.560 & 0.758 & 0.249 & 0.956 \\
\hline TIA & 0.717 & 0.111 & 0.493 & 0.735 & 0.131 \\
\hline Kidney disease & 0.769 & 0.335 & 0.880 & 0.139 & 0.924 \\
\hline Diabetes mellitus & 0.826 & 0.117 & 0.325 & 0.627 & 0.348 \\
\hline Arrhythmia & 0.866 & 0.915 & 0.728 & 0.107 & 0.633 \\
\hline Coffee consumption & 0.873 & 0.982 & 0.486 & 0.244 & 0.485 \\
\hline
\end{tabular}

other stroke. Statistically significant difference was observed only in the level of antibodies against Hsp72 $(p=0.046)$ and DnaJ $(p=0.022)$ in the group of patients that did and did not undergo a previous stroke (Fig. 2). That may also indicate a significant role of antibodies against bacterial Hsps in stroke and after stroke patient recovery.

By comparing the distribution of the antibody level in patients, we can notice an interesting correlation (Fig. 3). Only 33 percent of subjects in the patient group did not show elevated levels of antibodies against the proteins

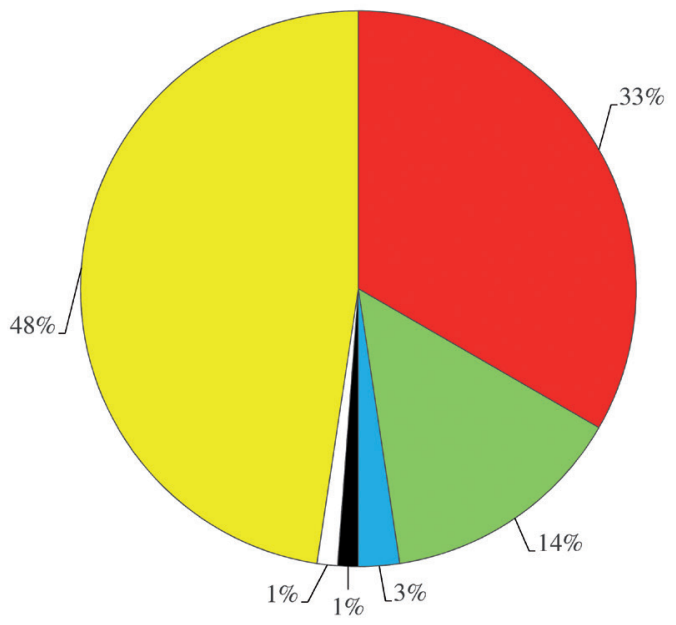

- No antibodies level elevated

$\square 1$ antibodies level elevated

$\square 2$ antibodies level elevated

- 3 antibodies level elevated

$\square 4$ antibodies level elevated

$\square 5$ antibodies level elevated

Figure 3. The percent of patients with elevated levels of antibodies anti-Hsp. examined here, while 48 percent of patients have elevatExplanation of this result may be a prevalence of bacteinfections, leading by cross-reaction to formation of

\section{DISCUSSION}

Early stage of atherosclerosis is characterized by an immune-mediated reaction, which may be caused by local autoantigens (Sigal, 2007). It has been described in the literature that Hsp and the oxidized low-density-lipoproteins (oxLDL) are the main autoantigens involved in the pathogenesis of atherosclerosis (Blasi, 2008). The role of Hsps in atherogenesis is not clear, although previous studies have demonstrated protection of endothelial cells from stress by Hsps (Johnson et al., 1993). Also, it has been shown that Hsps can stimulate plaque formation (Seitz et al., 1996). Presently it is assumed that the antibodies against microbial Hsps can be misdirected towards host Hsps overexpressed in the stressed cells of the vascular endothelium. In consequence, that may promote the plaque formation. This autoimmune reaction is possible because of the amino acid sequence similarity between microbial and human Hsp. While the bacterial Hsps have 97\% ho- 
mology between species, bacterial and human Hsps have more than 50\% homology (Young, 1992).

The DnaJ protein (Hsp40) is a co-chaperone for DnaK (Hsp70). It has been shown that the level of human Hsp40-HDJ-2 is significantly increased in atherosclerotic carotid artery and correlates with luminal stenosis in ulcerated atherosclerosis. It has been also shown that HDJ-2 and Hsp70 are present in atherosclerotic carotid artery plaques and expressed independently. Since bacterial DnaJ's N-terminal region is highly conserved between species, it is possible that an immunological cross-reaction between human Hsps and bacterial DnaJ-DnaK system takes place by shared B- and T-cell epitopes.

Another well-studied bacterial protein, GroEL, belongs to the Hsp60 family. The Hsp60 family is one of the most interesting groups of Hsps because of its wide range of effects on the development of autoimmune diseases. The Hsp60 family has been demonstrated to be involved in the development of rheumatoid arthritis in humans, adjuvant arthritis and insulin-dependent diabetes mellitus in rodents. Also, microbial Hsp60s are involved in pathogenesis of systemic sclerosis, psoriasis, Kawasaki disease, and Behcet's disease (Perschinka et al., 2003). It has been also shown that Hsp60 has a pathogenic role in cellular immune reactions in early human atherosclerosis (Knoflach et al., 2007). Bacterial Hsp60 stimulates the release of pro-inflammatory cytokines and cell adhesion in atherosclerotic lesions (Rupinder et al., 2001). It has been shown as well that antibodies that display cross-reactivity between human and microbial Hsp60 are related to atherosclerosis (Xu et al., 1999). Hsp60 localizes in atherosclerotic lesions of the arterial wall, whereas in nonatherosclerotic regions Hsp60 is not observed ( $\mathrm{Kol}$ et al., 1998). Also, Hsp60 reactive T-lymphocytes promote atherosclerosis development (Almanzar et al., 2012). It was demonstrated that bacterial Hsp60 is a major epitope that could cause autoimmunity for producing antibodies reactive to their human counterpart (Okada et al., 2007). Also, periodontopathic bacterial infection elevates levels of cross reactive antibodies between human Hsp60 and bacterial GroEL (Tabeta et al., 2000). In another study it was shown that there is a correlation between level of antibodies against Hsp60 and prevalence of coronary artery disease (Knowlton et al., 2008).

The presence of antibodies against GroEL in the group of stroke patients could be caused by previous bacterial infections. The acute phase of stroke induces stressful conditions with subsequent increase of Hsp's expression. Because of high concentration of Hsps in plasma, the antibodies can act less specificly. Therefore, given the similarity of amino acid sequence between bacterial and human Hsps, it is highly possible that the immune response to Hsps derived from pathogens might cross-react with host Hsps.

Similar assumption as we described above for the GroEL protein can be also made in relation to DnaK because of the close structural homology with human Hsp. It has been shown that E. coli DnaK and human Hsp70 are 50\% identical (Man-Un Ung et al., 2013) at the amino acid sequence level, so the immunological cross-reactivity is also possible in this instance. Hsp 70 may play a dual function in atherosclerosis. On one hand Hsp70 may act as a cytoprotector, a chaperone and play a role as an anti-apoptotic protein, reducing the level of Bax and AIF proteins synthesized in the cells of hypoxic tissue. (Goel et al., 2010). On the other, may stimulate the innate immune response and promote inflammation (Dvoriantchikova et al., 2014).
It has been shown that there is a correlation between anti-Hsp70 antibody level and the presence of vascular diseases such as claudication, critical ischemia and aneurismal disease (Chan et al., 1999). It is interesting that HSP70 mRNA expression during heat shock was higher than during postischemic reperfusion (Nishizawa et al., 1996). Hsp72 overexpression during stroke and its similarity to prokaryotic Hsp70 can also lead to immunological cross reaction, but levels of antibodies against Hsp72 display no differences between the patient and control groups.

We also measured antibodies level in plasma against the HtpG protein which is a distant eukaryotic relative of the human Hsp90 and actually is not well characterized. HtpG has about $40 \%$ sequence identity and 55\% similarity to its eukaryotic counterparts (Qing Huai et al., 2005). Human Hsp90 regulates the conformation, activation and function of over 100 cellular proteins. It has been shown that Hsp90 expression level is higher in atherosclerotic plaques compared with expression in normal artery. Hsp90 induces an immune response which makes Hsp90 a target autoantigen in the pathogenesis of atherosclerosis (Businaro et al., 2009). It is supposed that Hsp90, like other Hsps, is sustaining inflammatory mechanisms underlying pathogenesis of atherosclerosis (Benagiano et al., 2003). Reperfusion induces expression of Hsp90 in the heart, brain and kidney. Hsp90 overexpression in the ischemic region can preserve the tissue from damage through an exquisite stimulation of the endothelial NO pathway (Kupatt et al., 2004) and maintain activity of the proteasome in hypoxic cells (Hota et al., 2010). It has been observed that the HSP90 mRNA expression was significantly higher in reperfused hearts than in heat-shocked hearts (Nishizawa et al., 1996). It is possible that after stroke the level of Hsp90 suddenly increases and antigen-presenting cells produced during the earlier bacterial infection can redirect immune response against native Hsp90.

Possibly the high concentration of anti-Hsp72, antiDnaJ and other antibodies in plasma after the first stroke cause increased immune response against these proteins during another stroke. The more intensified immune response against Hsp72 may be caused by increased expression against this protein during the first stroke and next autoimmunization. Increased level of antibodies against DnaJ in the group of stroke patients may be related to its participation in Hsp40/Hsp70 co-chaperone system. Increased expression of human Hsp40/Hsp70 co-chaperone system during the stroke may lead to autoimmunization against human Hsp40 and in consequence may cause the immunological cross-reaction against bacterial DnaJ.

Our results suggest an essential role of Hsps in development of the atherosclerosis and stroke. Still, the exact role of Hsps in autoimmune diseases and stroke remains unclear and requires further studies.

\section{REFERENCES}

Almanzar G, Öllinger R, Leuenberger J, Onestingel E, Rantner B, Zehm S, Cardini B, van der Zee R, Grundtman C, Wick G (2012) Autoreactive HSP60 epitope-specific T-cells in early human atherosclerotic lesions. J Autoimmunology 39: 441-450

Banecki B, Kaguni JM, Marszalek J (1998) Role of adenine nucleotides, molecular chaperones and chaperonins in stabilization of DnaA initiator protein of Escherichia coli. Biochim Biophys Acta 1442: 39-48.

Banecki B, Liberek K, Wall D, Wawrzynów A, Georgopoulos C, Bertoli E, Tanfani F, Zylicz M (1996) Structure-function analysis of the zinc finger region of the DnaJ molecular chaperone. J Biol Chem. 271: 14840-14848. 
Beere HM (2005) Death versus survival: functional interaction between the apoptotic and stress-inducible heat shock protein pathways. $J$ Clin Invest 115: 2633-2639.

Benagiano M1, Azzurri A, Ciervo A, Amedei A, Tamburini C, Ferrari M, Telford JL, Baldari CT, Romagnani S, Cassone A, D’Elios MM, Del Prete G (2003) T helper type 1 lymphocytes drive inflammation in human atherosclerotic lesions. Proc Natl Acad Sci USA 100: 6658-6663.

Berberian P, Myers W, Tytell M, Challa V, Bond M (1990) Immunohistochemical localization of heat shock protein-70 in normal-appearing and atherosclerotic specimens of human arteries. $\mathrm{Am} J$ Pathol 136: 71-80.

Blasi C (2008) The autoimmune origin of atherosclerosis. Atherosclerosis 201: 17-32.

Businaro R, Profumo E, Tagliani A, Buttari B, Leone S, D'Amati G, Ippoliti F, Leopizzi M, D’Arcangelo D, Capoano R, Fumagalli L, Salvati B, Riganò R (2009) Heat-shock protein 90: A novel autoantigen in human carotid atherosclerosis Atherosclerosis 207: 74-83.

Caplan AJ1, Mandal AK, Theodoraki MA (2007) Molecular chaperones and protein kinase quality control. Trends Cell Biol 17: 87-92.

Chan YC, Shukla N, Abdus-Samee M, Berwanger CS, Stanford J, Singh M, Mansfield AO, Stansby G (1999) Anti-heat-shock protein $70 \mathrm{kDa}$ antibodies in vascular patients. Eur J V asc Endovasc Surg 18: 381-385.

Dahiya V, Chaudhuri TK (2004) Chaperones GroEL/GroES accelerate the refolding of a multidomain protein through modulating on-pathway intermediates. J Biol Chem 289: 286-298.

Dvoriantchikova G, Santos A, Saeed A, Dvoriantchikova X, Ivanov D (2014) Putative role of protein kinase $C$ in neurotoxic inflammation mediated by extracellular heat shock protein 70 after ischemia-reperfusion. J Neuroinflammation 23: 81.

Georgopoulos C, Welch WJ (1993) Role of the major heat shock proteins as molecular chaperones. Annu Rev Cell Biol 9: 601-634.

Goel G, Guo M, Jamie Ding J, Dornbos III D, Ali A, Shenaq M, Guthikonda M, Ding Y (2010) Combined effect of tumor necrosis factor (TNF)-a and heat shock protein (HSP)-70 in reducing apoptotic injury in hypoxia: A cell culture study. Neurosci Lett 483: 162-166.

Grabowski M, Banasiuk R, Węgrzyn A, Kędzierska B, Lica J, BaneckaMajkutewicz Z, Banecki B (2012) Role of heat-shock proteins and cobalamine in maintaining methionine synthase activity. Acta Biochim Pol 59: 489-493.

Hartl FU (1996) Molecular chaperones in cellular protein folding. $\mathrm{Na}$ ture 381: $571-580$.

Hota S, Hota K, Prasad D, Ilavazhagan G, Singh B (2010) Oxidative-stress-induced alterations in $\mathrm{Sp}$ factors mediate transcriptional regulation of the NR1 subunit in hippocampus during hypoxia. Free Radic Biol Med 49: 178-191

Huai Q, Wang H, Liu Y, Kim HY, Toft D, Ke H (2005) Structures of the N-terminal and middle domains of E. coli Hsp90 and conformation changes upon ADP binding. Structure 13: 579-590.

Johnson AD, Berberian PA, Tytell M, Bond MG (1993) Atherosclerosis alters the localization of HSP70 in human and macaque aortas. Exp Mol Pathol 58: 155-168.

Kaźmierczuk A, Kiliańska ZM (2009) The pleiotropic activity of heatshock proteins. Postepy Hig Med Dosw 63: 502-521 (in Polish).

Knoflach M, Kiechl S, Mayrl B, Kind M, Gaston JS, van der Zee R, Faggionato A, Mayr A, Willeit J, Wick G (2007) T-cell reactivity against HSP60 relates to early but not advanced atherosclerosis. Atherosclerosis 195: 333-338.

Knowlton A, Srivatsa U (2008) Heat-shock protein 60 and cardiovascular disease: a paradoxical role. Future Cardiology 4: 151-161.

Kol A, Sukhova GK, Lichtman AH, Libby P (1998) Chlamydial heat shock protein 60 localizes in human atheroma and regulates macrophage tumor necrosis factor-alpha and matrix metalloproteinase expression. Circulation 98: 300-307.

Kuczyńska-Wiśnik D, Matuszewska E, Laskowska E (2010) Escherichia coli heat-shock proteins IbpA and IbpB affect biofilm formation by influencing the level of extracellular indole. Microbiology 156: 148157.
Kupatt C, Dessy C, Hinkel R, Raake P, Daneau G, Bouzin C, Boekstegers P, Feron O (2004) Heat shock protein 90 transfection reduces ischemia-reperfusion-induced myocardial dysfunction via reciprocal endothelial NO synthase serine 1177 phosphorylation and threonine 495 dephosphorylation. Arterioscler Thromb V asc Biol 24: 1435-1441.

Mehta TA1, Greenman J, Ettelaie C, Venkatasubramaniam A, Chetter IC, McCollum PT (2005) Heat shock proteins in vascular disease a review. Eur I V asc Endovasc Surg 29: 395-402.

Nakamoto H1, Fujita K, Ohtaki A, Watanabe S, Narumi S, Maruyama T, Suenaga E, Misono TS, Kumar PK, Goloubinoff P, Yoshikawa H (2014) Physical interaction between bacterial heat shock protein (Hsp) 90 and Hsp70 chaperones mediates their cooperative action to refold denatured proteins. J Biol Chem 289: 6110-6119.

Nishizawa J, Nakai A, Higashi T, Tanabe M, Nomoto S, Matsuda K, Ban T, Nagata K (1996) Reperfusion causes significant activation of heat shock transcription factor 1 in ischemic rat heart. Circulation 94: 2185-2192.

Okada T, Ayada K, Usui S, Yokota K, Cui J, Kawahara Y, Inaba T, Hirohata S, Mizuno M, Yamamoto D, Kusachi S, Matsuura E, Oguma K (2007) Antibodies against heat shock protein 60 derived from Helicobacter pylori: diagnostic implications in cardiovascular disease. I Autoimmun 29: 106-115.

Perschinka H, Mayr M, Millonig G, Mayerl C, van der Zee R, Morrison SG, Morrison RP, Xu Q, Wick G (2003) Cross-reactive B-cell epitopes of microbial and human heat shock protein 60/65 in atherosclerosis. Arterioscler Thromb Vasc Biol 23: 1060-1065.

Picard D (2005) Intracellular dynamics of the Hsp90 co-chaperone p23 is dictated by Hsp90. Exp Cell Res 312: 198-204.

Pockley AG (2001) Heat shock proteins, anti-heat shock protein reactivity and allograft rejection. Transplantation 71: 1503-1507.

Huai Q, Wang H, Liu Y, Kim H, Toft D, Ke H (2005) Structures of the N-terminal and middle domains of E. coli $\mathrm{Hsp} 90$ and conformation changes upon ADP binding. Structure 4: 579-90.

Richter K, Buchner J (2001) Hsp90: chaperoning signal transduction. J Cell Physiol 188: 281-290.

Rosenzweig R, Moradi S, Zarrine-Afsar A, Glover JR, Kay LE (2013) Unraveling the mechanism of protein disaggregation through a ClpB-DnaK interaction. Science 339: 1080-1083.

Sawuła W, Banecka-Majkutewicz Z, Kadziński L, Jakóbkiewicz-Banecka J, Wegrzyn G, Nyka W, Banecki B (2009) Homocysteine level and metabolism in ischemic stroke in the population of Northern Poland. Clin Biochem 42: 442-447.

Seitz CS, Kleindienst R, Xu Q, Wick G (1996) Coexpression of heatshock protein 60 and intercellular-adhesion molecule- 1 is related to increased adhesion of monocytes and $\mathrm{T}$ cells to aortic endothelium of rats in response to endotoxin. Lab Invest 74: 241-252.

Sigal LH (2007) Basic science for the clinician 44: atherosclerosis: an immunologically mediated (autoimmune?) disease. I Clin Rheumatol 13: $160-168$

Spence J, Georgopoulos P (1989) Purification and properties of the Escherichia coli heat shock protein. J Biol Chem 264: 4398-4403.

Tabeta K, Yamazaki K, Hotokezaka H, Yoshie H, Hara K (2000) Elevated humoral immune response to heat shock protein 60 (hsp60) family in periodontitis patients. Clin Exp Immunol 120: 285-293.

Ung P, Thompson A, Chang L, Gestwicki J, Carlson H (2013) Identification of key hinge residues important for nucleotide-dependent allostery in E. coli Hsp70/DnaK. PLoS Comput Biol 9: e1003279.

Wawrzynów A, Banecki B, Wall D, Liberek K, Georgopoulos C, Zylicz M (1995) ATP hydrolysis is required for the DnaJ-dependent activation of DnaK chaperone for binding to both native and denatured protein substrates. J Biol Chem 270: 19307-19311.

Woo KM, Kim KI, Goldberg AL, Ha DB, Chung CH (1992) The heat-shock protein ClpB in Escherichia coli is a protein-activated ATPase. J Biol Chem 267: 20429-20434.

Xu Q (2002) Role of heat shock proteins in atherosclerosis, arteriosclerosis. Thromb Vasc Biol 22: 1547-1559.

Young DB (1992) Heat-shock proteins: immunity and autoimmunity. Curr Opin Immunol 4: 396-400. 